\title{
Development of a Taping Method to Prevent Osgood-Schlatter Disease Onset in Adolescent Male Soccer Players
}

\author{
Hiroyuki Watanabe*1, Meguru Fujii ${ }^{2}$, Masumi Yoshimoto ${ }^{3}$, Ryota Kuratsubo ${ }^{4}$, Reiji Higashiyama ${ }^{5}$ and Naonobu \\ Takahira
}

${ }^{1}$ School of Allied Health Sciences, Japan

${ }^{2}$ Nishifuna Clinic, Japan

${ }^{3}$ Department of Physical Therapy, Japan

${ }^{4}$ Department of Rehabilitation, Japan

${ }^{5}$ Department of Orthopedic Surgery, Japan

Received: 制: December 28, 2018; Published: 制: January 11, 2019

*Corresponding author: Hiroyuki Watanabe, School of Allied Health Sciences, 1-15-1 Kitasato, Minami-ku, Sagamihara, Kanagawa 252-0373, Japan

\begin{abstract}
Osgood-Schlatter disease is the most common type of knee joint injury among adolescent male soccer players. To clarify the cause of OsgoodSchlatter disease in adolescent soccer players, we previously measured the position of the center of gravity during the kicking motion. It was revealed that the center of gravity during the kicking motion was backward in soccer players who developed Osgood-Schlatter disease. The purpose of the present study was to develop a taping method (prevention tape) to prevent backward center of gravity during the kicking motion and therefore to prevent the onset of Osgood-Schlatter disease. The participants recruited for this study were 36 boys from two soccer teams of an elementary school, with a mean age of $10.2 \pm 0.4$ years. The three-dimensional coordinates of the markers were calculated using a three-dimensional video motion analysis system. The center of gravity was measured by Yokoi's method, using body part coefficients. A net was set up $3 \mathrm{~m}$ away from the ball and $1 \mathrm{~m}$ above the ground in order to measure the kicking motion. When applying the prevention tape, the patella was pulled downward by the traction force of the tape. We investigated the difference in the position of the center of gravity during kicking motion with or without prevention tape. In adolescent soccer players with prevention tape during the kicking motion, center of gravity changed to be significantly more forward than that in players without prevention tape.
\end{abstract}

Keywords: Osgood-Schlatter disease; Taping; Prevention; Soccer; Adolescence

Abbreviations: OSD: Osgood-Schlatter Disease; COG: Center of Gravity

\section{Introduction}

Adolescent athletes who are active during a growth spurt may develop epiphysitis at multiple sites, and many sports injuries in adolescent athletes are caused by the architectural fragility of the epiphysis [1,2] for example, elbow joint injuries in baseball players and knee joint injuries in soccer players [3]. Osgood-Schlatter disease (OSD) is the most common type of knee joint injury among adolescent male soccer players [4-6]. Osgood-Schlatter disease is caused by traction apophysitis of the tibial tuberosity because of repetitive strain from the quadriceps muscle. To clarify the cause of OSD in adolescent soccer players, Watanabe et al. measured the position of the center of gravity (COG) during the kicking motion. It was revealed that the COG during the kicking motion was backward in the soccer players who developed OSD [7]. Recently, it has been reported that taping methods can influence the potential of muscle force. However, many reports have not achieved a clear conclusion of how to increase muscle force by using taping methods [8-10]. If the taping increases the muscle force, it should also have effect on a position of the joints during sports activities. The purpose of this study is to develop a taping method (prevention tape) to prevent the backward COG during the kicking motion and therefore to prevent the onset of OSD in adolescent male soccer players. 


\section{Materials and Methods}

\section{Participants}

The participants recruited for this study were 37 boys from two soccer teams of an elementary school (mean age, $10.2 \pm 0.4$ years; mean height, $139.0 \pm 5.8 \mathrm{~cm}$; mean weight, $33.0 \pm 5.6 \mathrm{~kg}$; mean body-mass index (BMI), $17.1 \pm 2.0$ ). Participants were all Japanese male athletes on the same team and in the same grade at school. For participant selection, the conditions were set as above in order to address inclusion bias when examining teams belonging to different cities or teams with nearly equal competitive results. Exclusion criteria included pre-existing sports injuries of the knee such as OSD, Sinding-Larsen-Johansson disease, and patellar tendinitis. The participants provided written informed consent before participating in the study, and the study protocol was approved by an institutional research ethics committee.

\section{Procedure}

The measurement procedures at baseline included a questionnaire followed by a physical examination and screening for lower limb injuries. Reflective markers with a diameter of $1 \mathrm{~cm}$ were fixed in 25 places across the body: top of the head, earlobe (occipital), superior border of sternum, bilateral acromia, elbow joints, wrist joints, third metacarpophalangeal joints, greater trochanters, knee joints, lateral malleoli, toes, heels, and iliac crests, as well as on the spinous processes of the eighth thoracic vertebra and the superior border of the sacrum. The threedimensional coordinates of the markers were calculated using a three-dimensional video motion analysis system (Frame-DiasIV, DKH Corp, Tokyo). Three-dimensional video motion analysis was performed under two conditions: before and after attachment of prevention tape. COG measurements were obtained according to Yokoi`s method using body part coefficients [11]. A net was set up 3 $\mathrm{m}$ away from the ball and $1 \mathrm{~m}$ above the ground in order to measure the kicking motion (Figure 1).

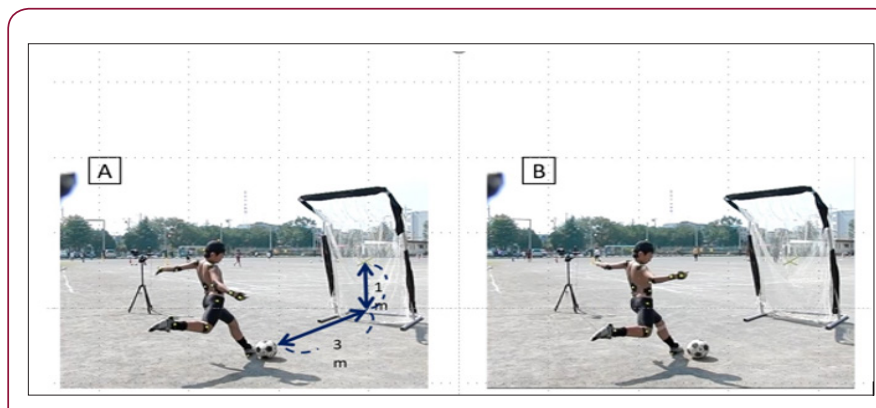

Figure 1: Typical view of the kicking motion in pre(A: non-tape condition) and post- (B: tape condition) conditions. A net was set up $3 \mathrm{~m}$ away from the ball and the target was $1 \mathrm{~m}$ above the ground. Measurement of the COG was obtained according to Yokoi's method using body part coefficients.

Four high-speed cameras (EXILIM EX-F1, Casio Corp, Tokyo) were arranged at intervals of $4.5 \mathrm{~m}$ at 60 degrees, 150 degrees, 210 degrees, and 330 degrees around the subject. Filming continued until the ball hit the target three times. Of the three filmed trials under each condition, the trial with the greatest ball impact was used for analysis. Kicking evaluations were made on the basis of the distance of the lateral malleolus of the support leg's fibula from the COG during the kicking phase (COG distance). The COG distance was measured as the distance directly from the lateral malleolus to the COG (L1) and the distance on the X-Y plane (L2). The COG distance at foot contact and ball impact were also calculated (Figure 2). The prevention tape was made into an original shape to assist with knee extension force and pain relief (Japanese Patent Application No. 2013-230195). When applying the prevention tape, the patella was pulled downward by the traction force of the tape (Figure 3). Since the prevention tape was processed beforehand, our young participants could easily attach it to their own knees. We investigated the difference in the position of COG during the kicking motion in the pre- and post-tape conditions.

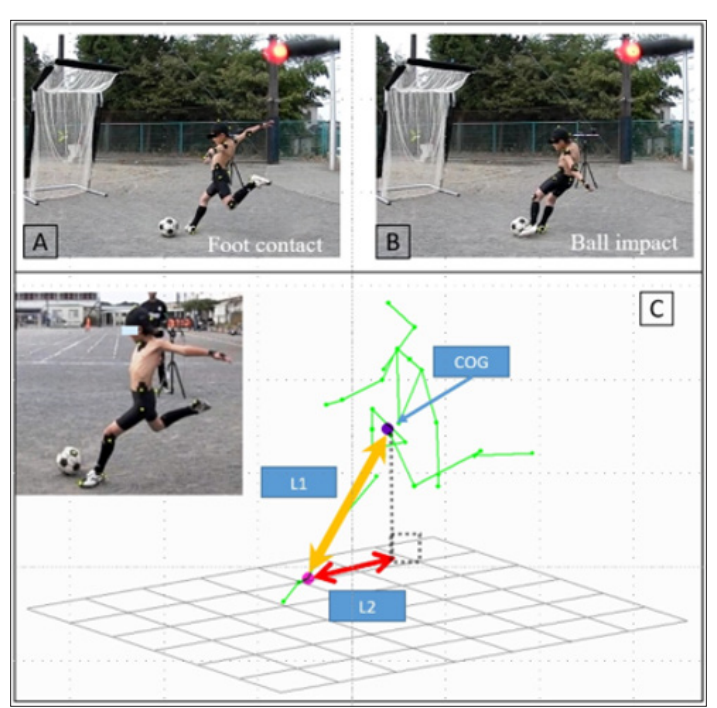

Figure 2: Measurement of the COG distance. Images A and B show the definition of posture during the kicking motion. Image $\mathrm{C}$ shows the method for calculation of the COG distance.

L1: Distance from the lateral malleolus of the support leg to COG (yellow).

L2: Distance from the lateral malleolus of the support leg to COG on the X-Y plane (red). 


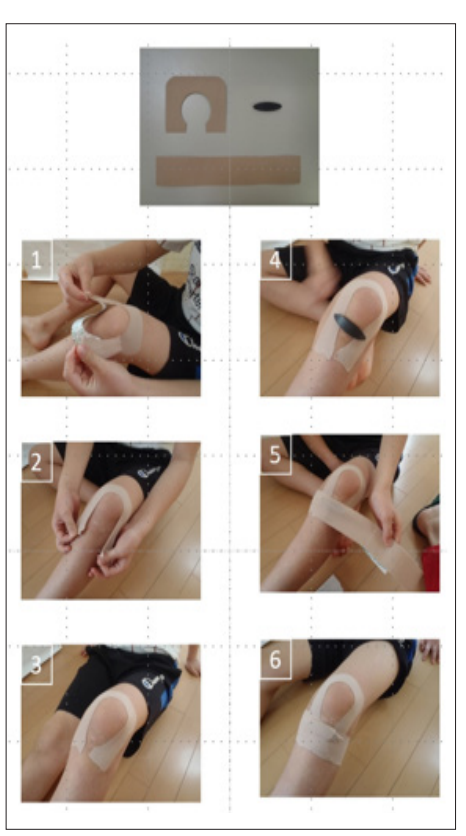

Figure 3: Taping method to prevent Osgood-Schlatter disease.

\section{Statistical Analysis}

The data were analyzed with SPSS v.22.0 (IBM Corporation, Armonk, NY, USA). Mean values and standard deviations were calculated for each condition. The level of significance was set to $5 \%$ and a two-tailed test (Student's t-test) was performed.

\section{Results}

In this study, one participant met the exclusion criteria for pre-existing OSD; therefore, 36 participants were included in the analyses. Figure 4 shows the data reflecting the COG distance under the two conditions and the statistical comparison of these data. In the distance from the lateral malleolus of the support leg to the COG (COG distance), there was no significant difference between the tape and non-tape conditions in the foot contact (tape: $0.81 \pm 0.06$ $\mathrm{m}$, non-tape: $0.84 \pm 0.08 \mathrm{~m}$ ) and ball impact (tape: $0.68 \pm 0.05 \mathrm{~m}$, nontape: $0.69 \pm 0.06 \mathrm{~m}$ ). In the distance from the lateral malleolus of the support leg to the COG on the X-Y plane, there were no significant differences between the tape condition or non-tape conditions in the foot contact (tape: $0.39 \pm 0.06 \mathrm{~m}$, non-tape: $0.43 \pm 0.10 \mathrm{~m}$ ), but the tape condition was significantly lower compared to the nontape condition in the ball impact (tape: $0.16 \pm 0.04 \mathrm{~m}$, non-tape: $0.19 \pm 0.05 \mathrm{~m})$.

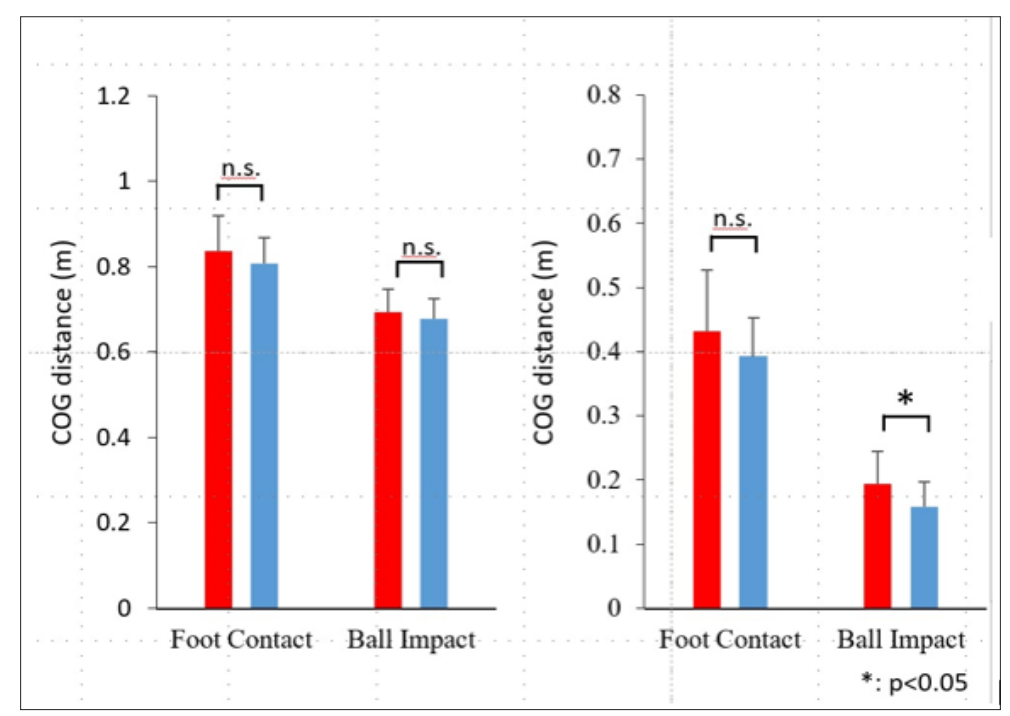

Figure 4: Comparison of tape condition (blue) with non-tape condition (red) in the COG distance on the direct and X-Y planes. The tape condition was significantly lower compared to the non-tape condition at the time of ball impact. Error bars represent the standard error of the mean.

\section{Discussion}

OSD is known to occur as a result of traction stress to the secondary ossification center of the tibial tuberosity by the patellar tendon. For this reason, OSD onset is strongly related to the growth process of the secondary ossification center of the tibial tuberosity [12]. This growth process is classified into four stages: the cartilaginous stage (ages 0-11 years), the apophyseal stage (ages 11-14 years), the epiphyseal stage (ages 14-18 years), and the bony stage (ages $>18$ years) $[13,14]$. It has been reported that the onset of OSD occurs more frequently in the apophyseal stage of development [15]. The mean age in this study (10.2 \pm 0.4 years) is close to the apophyseal stage. The peak onset age for OSD is before the ages of 15 to 18 years $[16,17]$. Therefore, to perform preventive research on OSD, it is necessary to recruit the participants before they reach this age [18]. One participant in this study was excluded because of a prior history of OSD, but all other participants were recruited before the onset of OSD.

There are many reports on the risk factors associated with the onset of OSD. Risk factors for adolescent soccer players include the period and intensity of growth spurts, increased tightness of the 
quadriceps femoris muscle, lower limb malalignment, presence of preceding apophysitis, and the backward COG during the kicking motion [19-21]. It has been reported that kicking with the trunk inclined backward can shift the COG posteriorly, increasing the knee extension force in the support leg $[7,22,23]$. Since prevention of the onset of OSD in adolescent soccer players is influenced by physical characteristics in addition to growth spurts, it is important to undertake preventive strategies with conditioning exercises such as stretching, range of motion (ROM) exercises, and coordination exercises. However, intervention in elementary school age children for improving the kicking motion is difficult. In this study, significant differences were not measured in the COG distance, including vertical components (L1) at the COG position during the kicking motion.

Since a significant difference was observed in the COG on the $\mathrm{X}-\mathrm{Y}$ plane (L2), it is possible that elementary school age children during growth spurts may make errors in the vertical component of the kicking motion. Historically, taping has been performed for athletes with the aim of pain relief [24]. However, as demonstrated by the role of prevention tape of this study, it is possible to use taping for traction. In this study, tape was used to pull the patella downward to assist the extension force of the knee, and it had the function of suppressing the backward COG during the kicking motion. In our results, the position of the COG during the kicking motion at the time of ball impact decreased significantly in the tape condition compared with the non-tape condition. Although the difference in the COG position due to the presence or absence of tape is on average only $4 \mathrm{~cm}$, it may be possible to reduce the onset of OSD by using prevention tape together with conventional conditioning methods. It is difficult in practice to use taping for elementary school children, and the assistance of coaches or parents may be necessary. The prevention tape of this study was made such that elementary school children could attach it to their own knees. However, continuous use of tape is more expensive than knee braces and may not be economically feasible.

\section{Limitations}

In the three-dimensional video motion analysis, the experimental environment was each team's playing ground, so we were unable to use a floor gauge to measure the ground-reaction forces. As a result, it was not possible to calculate the extension force of the knee joint during the kicking motion.

\section{Conclusion}

We developed a taping method for OSD prevention and analyzed the effects of this tape on the kicking motion using a threedimensional video motion analysis system. In total, 36 adolescent soccer players were analyzed during the kicking motion under pre- and post-tape conditions. In adolescent soccer players with prevention tape during the kicking motion, COG changed to be significantly more forward than that in players without prevention tape. From the viewpoint of the three-dimensional video motion analysis, the OSD prevention tape was recognized to be effective in preventing the onset of OSD in adolescent soccer players.

\section{Acknowledgement}

The authors acknowledge the athletes, parents, and coaches from the two soccer teams in Tokyo and Kanagawa prefecture.

\section{References}

1. De Lucena GL, Dos Santos Gomes C, Guerra RO (2011) Prevalence and associated factors of Osgood-Schlatter syndrome in a population-based sample of Brazilian adolescents. Am J Sports Med 39: 415-420.

2. Blankstein A, Cohen I, Heim M, Diamant L, Salai M, et al. (2001) Ultrasonography as a diagnostic modality in Osgood-Schlatter disease. A clinical study and review of the literature. Arch Orthop Trauma Surg 121(9): 536-539.

3. Kerssemakers SP, Fotiadou AN, De Jonge MC, Karantanas AH, Maas M (2009) Sport injuries in the paediatric and adolescent patient: A growing problem. Pediatr Radiol 39(5): 471-484.

4. Nakase J, Goshima H, Numata H, Oshima T, Takata Y, et al. (2015) Precise risk factors for Osgood-Schlatter disease. Arch Orthop Trauma Surg 135(9): 1277-1281.

5. Perhamre S, Lundin F, Norlin R, Klässbo M (2011) Sever's injury; treat it with a heel cup: A randomized, crossover study with two insole alternatives. Scand J Med Sci Sport 21(6): 1-6.

6. Šarčević Z (2008) Limited ankle dorsiflexion: A predisposing factor to Morbus osgood schlatter? Knee Surgery, Sport Traumatol Arthrosc 16(8): 726-728.

7. Watanabe H, Fujii M, Yoshimoto M, Abe H, Toda N, et al. (2018) Pathogenic Factors Associated with Osgood-Schlatter Disease in Adolescent Male Soccer Players: A Prospective Cohort Study. Orthop J Sports Med 6(8): 1-8.

8. Dos Santos AN, Rocha NACF (2018) Immediate effect of kinesio taping on knee extensor torque of children with Cerebral Palsy: Three case reports. Neuro Rehabilitation (8): 1-5.

9. Jafarnezhadgero A, Shad MM, Majlesi M, Zago M (2018) Effect of kinesio taping on lower limb joint powers in individuals with genu varum. J Bodywork Movement Ther 22(2): 511-518.

10. Serra MVGB, Vieira ER, Brunt D, Goethel MF, Gonçalves M, et al. (2015) Kinesio Taping effects on knee extension force among soccer players. Braz J Phys Ther 19(2): 152-158.

11. Yokoi T, Shibukawa K, Ae M (1986) Body segment parameters of Japanese children. Jap J Phys Educ 31(1): 53-66.

12. Blankstein A, Cohen I, Heim M, Diamant L, Salai M, et al. (2001) Ultrasonography as a diagnostic modality in osgood-Schlatter disease. Arch Orthop Trauma Surg 121(9): 536-539.

13. Ehrenborg G, Lagergren C (1961) Roentgenologic changes in the OsgoodSchlatter lesion. Acta Chirurgica Scand 121: 315-327.

14. Ducher G, Cook J, Lammers G (2010) The ultrasound appearance of the patellar tendon attachment to the tibia in young athletes is conditional on gender and pubertal stage. J Sci Med Sport 13(1): 20-23.

15. Kaneuchi Y, Otoshi K, Hakozaki M, Sekiguchi M, Watanabe K, et al. (2018) Bony Maturity of the Tibial Tuberosity with Regard to Age and Sex and Its Relationship to Pathogenesis of Osgood-Schlatter Disease: An Ultrasonographic Study. Orthop J Sports Med 6(1).

16. Çakmak S, Tekin L, Akarsu S (2014) Long-term outcome of OsgoodSchlatter disease: not always favorable. Rheumatol Int 34(1): 135-136.

17. Gholve PA, Scher DM, Khakharia S, Widmann RF, Green DW (2007) Osgood Schlatter syndrome. Curr Opin Pediatr 19(1): 44-50.

18. Rössler R, Junge A, Chomiak J, Dvorak J, Faude O (2016) Soccer Injuries in Players Aged 7 to 12 Years. Am J Sports Med 44(2): 309-317.

19. Rauch F, Bailey DA, Baxter-Jones A, Mirwald R, Faulkner R (2004) The

Cite this article: Hiroyuki W, Meguru F, Masumi Y, Ryota K, Reiji H, Naonobu T. Development of a Taping Method to Prevent Osgood-Schlatter Disease Onset in Adolescent Male Soccer Players. Biomed J Sci \& Tech Res 13(1)-2019. BJSTR. MS.ID.002350. DOI: 10.26717/ BJSTR.2019.13.002350. 
"Muscle-Bone Unit" during the pubertal growth spurt. Bone 34(5): 771775.

20. Weiler R, Ingram M, Wolman R (2011) 10-Minute Consultation. Osgoodschlatter disease. BMJ 343: d4534.

21. Gigante A, Bevilacqua C, Bonetti MG, Greco F (2003) Increased external tibial torsion in Osgood-Schlatter disease. Acta Orthop Scand 74(4): 431-436.

ISSN: 2574-1241

DOI: $10.26717 / B J S T R .2019 .13 .002350$

Hiroyuki Watanabe. Biomed J Sci \& Tech Res

(C) (i) This work is licensed under Creative

Submission Link: https://biomedres.us/submit-manuscript.php
22. Blackburn JT, Padu A (2009) Sagittal-plane trunk position, landing forces, and quadriceps electromyographic activity. J Athl Train 44(2): 174-179.

23. Lees A, Asai T, Andersen TB, Nunome H, Sterzing T (2010) The biomechanics of kicking in soccer: a review. J Sports Sci 28(8): 805-817.

24. Chao YW, Lin JJ, Yang JL, Wang WTJ (2015) Kinesio taping and manual pressure release: Short-term effects in subjects with myofasical trigger point. J Hand Ther 29(1): 23-29.

$\begin{array}{ll}\text { BIOMEDICAL } & \text { Assets of Publishing with us } \\ \text { RESEARCHES } & \text { - Global archiving of articles } \\ & \text { - Immediate, unrestricted online access } \\ & \text { - Rigorous Peer Review Process } \\ \end{array}$

